\title{
HABLEMOS CON LAS MARIPOSAS
}

\author{
CLAUDIA ANDREA LONDOÑO RESTREPO \\ Química Universidad del Quindío, \\ Magíster en Medio ambiente y desarrollo Universidad Nacional de Colombia, \\ Candidata a Doctora en educación Universidad Bolivariana de Chile \\ argemamoenas@gmail.com
}

\section{Cómo citar este artículo:}

Londoño, C. (2011). Hablemos con las mariposas. Espiral, Revista de Docencia e Investigación. . Espiral, Revista de Docencia e Investigación. 1, (1), 21 - 26

\begin{abstract}
Resumen
Esta propuesta educativa compara el paso por la niñez y la adolescencia con la vida de una mariposa, se escogió esta metáfora con el fn de llevar hasta la piel de los docentes la fragilidad, brevedad y difcultad de este periodo de la vida que transcurre en la escuela. Para abrir caminos rizomáticos que permitan múltiples posibilidades de acercamiento al mundomariposa, se propone tejer el proceso educativo sobre cuatro urdimbres: la teoría de la cognición, la experiencia del cuerpo, la importancia de la palabra y las innovaciones tecnológicas.
\end{abstract}

Palabras clave: educación, proceso cognitivo, lenguajes, tecnología, cuerpo.

\begin{abstract}
This educative proposal compares the step through the childhood and adolescence with the life of a butterfy. I chose this metaphore in order to transmit to the teachers' skin the fragility, briefness and diffculty of this period of life that happens at school. To open several ways that allow lots of possibilities of approaching to the world of the butterfy, it is a proposal to weave the educational process in four dimensions: the cognition theory, the body experience, the importance of the speech and the technological innovations.
\end{abstract}

Key words: education, cognitive process, languages, technology, body.

\section{Introducción}

Decisivamente nos encontramos ante la urgente necesidad de reconocer sin ambages que el pensamiento moderno o, por ex- tensión, la ciencia newtoniana, no nos permite afrontar la complejidad del problema del desarrollo y viabilidad de los procesos educativos. En este sentido la educación se compromete a dar continuidad a un sistema escolar que perpetúe e imponga leyes, saberes y castigos, es decir, la pedagogía como un dispositivo de poder que modela y administra el pensamiento (Ortega, 2005, 20).

Así pues, es inaplazable el trabajo con las ciencias contemporáneas (también llamadas ciencias de la vida y de la complejidad), en cuyos conceptos hay un horizonte de posibilidades para un nuevo pensamiento que supere las dicotomías (sujeto u objeto, sustancia extensa o sustancia pensante, Ser o no Ser, bien o mal, mundo real o mundo aparente y todas las demás) la simplicidad, el reduccionismo y se acerque a los quiebres y discontinuidades de la naturaleza-vida (Prigogine, 1996).

Por lo anterior es la pedagogía que deviene en las ciencias de la vida y la complejidad a la que hace alusión este trabajo. La educación se asume desde la complejidad de lo vivo como el escenario propicio para que emerja un conocimiento basado en el respeto y amor.

Desde este contexto se propone que la escuela es un sistema vivo impactado por las 
interacciones de todos los actores educativos. Es decir, el proceso educativo es el mismo proceso de la vida, o el proceso cognitivo y la teoría de la cognición nos remite a pensar que el conocimiento se logra a través del modo como un organismo interactúa con su entorno y se hace viable (Capra, 1998).

En la educación como proceso cognitivo se hace necesario recuperar el cuerpo como el lugar donde acontece lo ecosistémico y lo cultural (Noguera, 2000). Recuperar el cuerpo, es recuperar la dimensión de lo lúdico y lo erótico, de lo visual, lo táctil y lo sensible, en todas sus formas. Además reconocer que el cuerpo es intervenido y reconstruido, lo que hace necesario incluir en este traba-
En la educación como proceso cognitivo se hace necesario recuperar el cuerpo como el lugar donde acontece 10 ecosistémico y lo cultural jo dos espacios de intervención de lo humano: el lenguaje de la diversidad, es decir, es necesario llevar al aula no sólo la voz de la ciencia, sino la voz de nuestras raíces campesinas, indígenas y negras y el nuevo espacio social que habitamos los humanos: la tecnología y las telecomunicaciones porque abren nuevas posibilidades para el desarrollo de procesos perceptivos y sensoriales.

\section{Hablemos con las mariposas}

Hoy estaré en silencio y muy atenta, hoy quiero escuchar las mariposas. $\mathrm{Su}$ aleteo no se detiene y cómo hacerlo si su vida es tan frágil, su lengua quiere probar todas las mieles y cómo dejar de saborear la vida que se acaba en un suspiro.

La vida del adolescente es como la vida de una mariposa. La niñez es muy corta, no han dejado de ser larvas cuando ya sus cuerpos se han vestido de colores, y cuando el azul es más brillante y el rojo reverdece en sus vestidos de viento, la calle anuncia que su adolescencia ha terminado y mueren sus etéreas vidas colorinas para nacer en los fríos días de la adultez.

Los docentes de las escuelas y colegios son testigos de este corto y ligero recorrido e igual que estas inquietas mariposas, no saben qué hacer con el reto que tienen ante sus ojos.

Quiero detenerme ante esta escena: un docente delante de un grupo de 50 adolescentes ávidos de caminos, buscadores de fortunas y sintiéndose los mejores amantes. Tienen el mundo en las manos y, justo en ese momento, el profesor viene a recitar una serie de palabras que ellos no quieren escuchar, un estudiante le dice: -Profe: ¿Y esto para qué nos sirve? En la lucha por responder a esa pregunta se choca con las hormonas, con los azúcares, con el amor. Pero su esfuerzo se ve reprimido porque ahora las niñas miran a través de las ventanas del colegio a los chicos que pasan y se escucha el sonido estridente de algunas motos.

Detiene su mirada en las niñas que ahora ni lo perciben, porque cuchichean y sonríen y nota que han pasado la noche cepillándose el cabello en lugar de hacer la tarea. Esta clase es justo a las siete de la mañana y el profesor ya está lleno de una gran desazón -'los tiempos han cambiado y a estos muchachos no los maneja nadie' dicen. -'Me voy, aquí ya no hay nada que hacer, los muchachos ya no quieren saber nada'.

Pero en el aire quedan las preguntas: ¿Qué puedo enseñarles? ¿Acaso el colegio es ajeno a la vida de estos jóvenes? ¿Cómo descubrir un poco ese mundo infatigable y penetrarlo? ¿Cómo llegar hasta sus vidas apáticas de nosotros?

En tal sentido esta propuesta de educación busca reconocernos vida y reinventar- 
nos cuerpo, aprendizaje y palabra, es decir, hacer del aula de clase un lugar de encuentros, de impulso a los sueños, un oído que escucha la angustia, un lu-

gar donde la educación sea el mismo proceso de la vida. Para esto se propone asumir la escuela como un sistema vivo, al que le ocurre la felicidad y el dolor. Un sistema en el que cada actor se reconozca un todo inserto
Asumiri la escuela como un sistema vivo, al que le ocuire la felicidad y el dolor. en un ambiente de relaciones. Así, el proceso educativo es un emergente de la relación ambiente-actores-territorio donde se hace necesario un lenguaje biocéntrico, bioético, esto quiere decir, un pensamiento a favor de la vida (Meneses, e Ingeborg, 2002).

El sistema vivo-escuela se mantiene gracias al fenómeno autopoiético, es decir, al acoplamiento estructural entre el interior de la escuela y el ambiente donde está inserta. Para lograr el mantenimiento de las redes autopoiésicas se debe invitar al interior de nuestras clases cuatro aliados: la educación como proceso cognitivo, la experiencia del cuerpo, la importancia de la palabra y las innovaciones tecnológicas.

En la educación como proceso cognitivo encontramos que el conocimiento se logra cuando el sistema interactúa con el entorno y se acopla estructuralmente a él para mantener el patrón de organización o autopoiésis (Maturana y Varela). Un sistema autopoiético es aquel que se produce a sí mismo, lo que se indica al designar la organización que los defne, como organización autopoiética. La característica más peculiar de un sistema autopoiético es que se levanta de sus propios cordones y se constituye como distinto del medio circundante a través de su propia dinámica, de tal manera que ambas cosas son inseparables (Maturana y Varela, 1984, 28).Cognición entonces incluye: percepción, emoción y acción, por consiguiente, todo organismo es capaz de percibir su entorno, por tanto, conocerlo y transformarse en él.

Además, de una dimensión de enlace o de conexión del sistema vivo con su medio ambiente el proceso cognitivo tiene una dimensión interpretativa, que son las huellas que dejamos en el ambiente que habitamos. Por ejemplo, un nido en un árbol es la huella de un ave, una cueva es la huella de un armadillo, una casa es la huella de un humano. De esta forma los estudiantes reconocen su conexión con el ambiente que habitan, se reconocen sistemas simbióticos, diferenciados e interconectados, y se circunscribe la vida de cada actor al proceso educativo.

El cuerpo es nuestra conexión con el ambiente en él se conjugan nuestra identidad biológica y cultural. Es importante que este cuerpo simbiótico no sea un cuerpo sumiso y relegado, por el contrario, sea experiencia en el aula. La escuela y la familia gustan de pedagogías moralistas y abstencionistas para teñir de matices de represión la relación con la sexualidad y el concepto de género.

La invitación es a poner sobre la mesa no sólo los discursos biológicos de la reproducción, sino la sexualidad del niño y del adolescente (Foucault, 1998), sus fantasías pueden quedar plasmados en sus dibujos y textos. Además es importante olvidar la idea de que sólo las diferencias en el cuerpo le proporcionan un signifcado a la imagen de hombre o mujer. Como dice Harawey "Cualquier sujeto fnalmente coherente es una fantasía y la identidad colectiva y personal es reconstruida socialmente de manera constante, el cuerpo es un discurso social abierto a la intervención“ (Harawey, 1995, 227-265).

Ahora, al vuelo de la mariposa se suman otros horizontes, en este trabajo se busca primero reconocer la educación como un 
acontecimiento ecológico de interacciones y corporeidad, $\mathrm{y}$, en un segundo momento, incluir dos espacios de interacción de lo diferencialmente humano en los que se generan diversas posibilidades educativas como son: la recuperación de la palabra, de los preconceptos, de los conocimientos populares y ancestrales como puntos de partida para una educación diversa e incluyente y las nuevas tecnologías de la información y de las telecomunicaciones como un nuevo espacio de interacción.

Es necesario incluir en la educación actual las voces campesinas, indígenas o, en general, la multiplicidad de voces que se reúnen en un proceso educativo, todos tenemos algo importante que decir, no sólo la ciencia es la voz de la verdad.

Cada mariposa tiene formas y colores diferentes, así mismo las diversas culturas viven infnitos dominios estéticos (Maturana, 1997, 60), esto es muy importante en la escuela ¿Qué es lo feo? ¿Qué es lo bello? La escuela excluye algunas expresiones e incluye otras negando la diversidad, por ejemplo se celebra el día de la imposición de la ceniza y se imprime en las frentes sudorosas de los jóvenes una cruz que simboliza que en polvo se convertirán en algún momento, pero no se celebran festas relacionadas con los embera chami que simbolizan nuestras raíces. Se encuentran asentamientos de esta comunidad indígena en los departamentos de Quindío, Caldas, Valle del Cauca y otros. Este grupo se destaca por la ubicación de sus asentamientos sobre las cuencas de los ríos, adaptados a los ecosistemas de selva húmeda tropical.

El lenguaje es una forma de vivir conjuntamente en un fujo de dominio consensual (Maturana, 1995, 39), esto quiere decir que el lenguaje se construye en nuestras relaciones, en el consenso con otros. Entre las personas que habitan un territorio común se produ- cen acuerdos, coordinaciones de aquello que les gusta, incluso lo que se considera malo o bueno. Debemos aceptar que nuestra corporeidad pone en evidencia a qué grupo pertenecemos, pero en realidad sólo es en la forma como nos relacionamos y construimos un lenguaje común que nos hacemos humanos (Maturana, 1997, 38- 39).

La educación debe ser un espacio abierto a los relatos individuales, a los relatos grupales, a los relatos plurales (Olivé, 2011), a lo que cada niño, cada joven trae en su mochila familiar o construye en sus relaciones. Es triste que el niño indígena quiera olvidar el mundo que lo hace diferente, pero es más triste que la escuela no se encargue de que todos aprehendamos y valoremos sus saberes.

Pero, además de reconocer la diversidad de lenguajes y de retomar los saberes olvidados también es importante reconocer que nuestras relaciones han cambiado. Las tecnologías posibilitan las relaciones a distancia y establecen relaciones transterritoriales y transtemporales, además permiten la emergencia de un nuevo espacio social que posibilita diversos procesos de aprendizaje y de transmisión del conocimiento importantes para las sociedades contemporáneas (Echeverría, 2006, 8).

Aunque la vida del humano está rodeada de celulares, televisores, Facebook, Internet, mariposas-avatar, no ha tenido un tiempo de preparación para asumir este nuevo espacio social. Se transita libremente por el tercer entorno como lo llama Echeverría pero la escuela es todavía la tradicional (Echeverría, 2000, 24).

Esta realidad hace necesario repensar la educación, si se tiene en cuenta que el crecimiento de la guerra, la investigación, los espectáculos, la sexualidad, la información electrónica y en general el tele mundo crece de manera vertiginosa. Estas nuevas formas 
de relacionarse traen insertos nuevos procesos perceptivos, es decir, nuevas formas de sentir, de amar, lo que hace necesario diseñar nuevas acciones educativas, complementarias a las ya existentes (Echeverría, 2000, 20).

Es necesario aprender a moverse con facilidad por el mundo de las telecomunicaciones por eso se debe realizar una acción educativa repensando los videojuegos, los programas de televisión, por ejemplo, que pedagogos puedan participar en su diseño. A la vez el celular, Facebook, el Internet en general sean medio de aprendizaje. Para esto es necesario que los profesores puedan ser teletutores o teleenseñantes (Echeverría, 2000,31 ), sin olvidar que muchos profesores aún no se defenden en el nuevo espacio social, y ven todas estas posibilidades tecnológicas como distractores.

Por lo tanto, no se asume el papel que debe desempeñar un docente en la generación de espacios adecuados para el aprendizaje. La sociedad de la información requiere un nuevo tipo de alfabetización, o, mejor, la adquisición de nuevas habilidades y destrezas para intervenir competentemente en el espacio telemático (Echeverría, 2000, 22), no podemos olvidar que América Latina recibe la ola expansiva de la explosión tecnológica, pero no ha sido nuestra propia iniciativa y quienes manejan la información también pueden manejar el poder.

Soy Mariposa hombre-mujer vestida-o de colores recorro los corredores de este viejo colegio. Hoy nuevo porque comienzo mi último grado de bachiller, veo llegar a mis compañeros y poco más altos y a mis compañeras un poco más esbeltas y ahora nos queda un último esfuerzo para dejar de habitar estos salones que me refugiaron durante 11 años de la vida, años en los que he cambiado vertiginosamente.
Aquí escribí mis primeras letras y, por primera vez, me quedé sola sin mi mamá y fuera de la casa. En este lugar pasé de medir metro y medio cuando estaba en transición, a medir hoy un metro setenta. Estos espacios fueron testigos de mis primeras lágrimas y primeras menstruaciones. Aquí encontré mis primeros amigos y mi primer novio, vi morir a mi amigo-profesor que nos enseñaba con una sonrisa dibujada en esa cara pequeña y arrugada, vi marcharse a tantos compañeros y docentes, a algunos ni siquiera les agité la mano al partir, otros dejaron dibujadas lágrimas de soledad en mí rostro. Aunque nunca me fui de este colegio si me cambié de casa y el tiempo pasó sin detenerse.

Profe: ¿Aún sigues pensando que esto no tiene importancia? ¿Qué no queremos aprender nada? $\mathrm{Y}$, que en este colegio no hay nada que hacer...

\section{Conclusión}

Queremos pensar que la conclusión es un espacio de esperanza, revela un reconfgurar, recomenzar, por eso podemos decir que lograr espacios para que los actores educativos participen de la construcción de los procesos que quieren y de la escuela que sueñan, es generar espacios para la emergencia de ciudadanía educadora, de valores a nivel personal, familiar y social, de reconocimiento de la diversidad.

Asumir el acto educativo desde la complejidad de lo vivo, entendido como autopoiésis, emergencia, evolución, naturaleza, cultura, permite una relación educativa entre personas con preocupaciones bioéticas y políticas, capaces de afrontar sus problemas y aprovechar las posibilidades a través de acciones democráticas, concertadas y participativas, desde un saber responsable de su ambiente y del proceso educativo como oportunidad para la sostenibilidad futura de la humanidad y de la vida misma. 


\section{Referencias bibliográfcas}

Capra, Fritjof (1998). La trama de la vida. Barcelona

España: editorial Anagrama.

Echeverría, J. (1999). Los señores del aire: Telépolis y el tercer entorno. España: destino.

Echeverría, J. (2000). Educación y tecnologías, TIC en la educación telemáticas. Revista IBERO AMERICANA Número 24.

Echeverría, J. Economía y sociedad en el espacio electrónico. Instituto de Filosofía, CSIC, Cuarto Congreso de Economía de Navarra, octubre de 2001.

Echeverría, J. (2005). Entrevista radial sobre la revolución tecno científca. España.

Echeverría, J. (2006). Tesis sobre el tercer entorno y la vida cotidiana. Madrid: Instituto de Filosofía, CSICC/ Pinar.

Echeverría, J. (2010). Congreso internacional de Filosofía de la ciencia, ponencia sobre las teorías científcas.

Foucault, M. (1998). Historia de la sexualidad l, la voluntad del saber. Vigésimo quinta edición en español. España: Siglo XXl editores s.a.

Foucault, M. (1998). Historia de la sexualidad ll, el uso de los placeres. Vigésimo quinta edición en español. España: Siglo XX1 ditores s.a.

Harawary Donna (1995). Ciencia Cyborg y Mujeres: La reinvención de la naturaleza. España: ediciones Cátedra.

Maturana Humberto R (1997). La realidad: ¿Objetiva o construida? I fundamentos biológicos de la realidad. Barcelona España: Anthropos Editorial.

Meneses Daniel F, Ingeborg Carvajal C (2002). Acercándonos a la bioética como una nueva inteligencia. Colombia: Universidad del Bosque, colección Pedagogía y Bioética.

Noguera, Ana P (2000). Educación Estética y complejidad ambiental, Universidad Nacional de Colombia.

Olivé, León (2000). El bien, el mal y la razón. Facetas de la ciencia y la tecnología. México: Paidós.

Ortega, José Olmedo (2005). Poder y práctica pedagógica. Colombia: editorial Magisterio.

Prigogine, Ilya (1996). Proceso al azar. Madrid España: Ediciones Cátedra. 